\title{
Performance of Recycled Plastic Pin (RPP) for Slope Stabilization
}

\author{
M.S. Khan ${ }^{1(\bowtie)}$, M. Sahadat Hossain ${ }^{2}$, M.A. Khan ${ }^{2}$, \\ and Mohammad Faysal ${ }^{2}$ \\ ${ }^{1}$ Department of Civil Engineering, Jackson State University, \\ 1400 John R Lynch Street, Jackson, MS 39217, USA \\ J00797693@jsums.edu \\ 2 Department of Civil Engineering, The University of Texas at Arlington, \\ 416 Yates Street NH 119, Arlington, TX 76019, USA \\ Hossain@uta.edu, \{md.khan22, md. faysal\}@mavs.uta.edu
}

\begin{abstract}
Surficial failures of highway slopes in clayey soils are quite common throughout the United States. These failures commonly occur for the slope constructed with expansive clay, especially after prolonged rainfall. These failures are also predominant in North Texas area and cause significant maintenance problems for the Texas Department of Transportation (TxDOT). As an alternative to the conventional slope stabilization technique, a green and cost effective slope stabilization method using the Recycled Plastic Pin (RPP) had been utilized and tested for its performance. RPPs are driven into the slope face to provide additional resistance along the slip surface, which increases the factor of safety against shallow slope failure. Current study summarizes the long term performance of a highway slope on expansive clay reinforced with RPP. The slope is located over US 287 near the St. Paul overpass in Midlothian, Texas. Surficial movement had taken place over the slope, resulting in cracks over the shoulder and near the bridge abutment. Three $50 \mathrm{ft}$. slope sections were stabilized using RPPs in March 2011. In addition, two $50 \mathrm{ft}$. unreinforced control sections were utilized between the reinforced sections to evaluate the performance of slope sections stabilized with RPP. After installation of the RPPs, the performance of the slope was monitored by using instrumented RPPs, inclinometers and topographic survey. The performance monitoring results indicate that, maximum deformation of the reinforced slope section is less than $3.75 \mathrm{~cm}$ (1.5 in.). However, more than $38 \mathrm{~cm}$ (15 in.) of vertical settlement was observed at the control sections during the last 5 years monitoring period. Also, few slope-sections just opposite side of reinforced slope at the same highway failed during the monitoring period. Based on the last 5 years monitoring data, it was summarized that RPP can be successfully utilized for slope stabilization.
\end{abstract}

\section{Introduction}

Shallow slope failure refers to surficial slope instabilities along highway cuts, fill slopes and embankments. Moderate-to-steep slopes and embankments underlain by expansive clay soils are susceptible to shallow landslides during intense and prolonged rainfall events. In many cases, the failure surface is parallel to the slope face. Shallow slope 
failures generally do not constitute a hazard to human life or cause major damage. However, they can be a hazard to infrastructure, by causing damage to guardrails, shoulders, road surfaces, drainage facilities, utility poles, and/or the slope landscaping (Titi and Helwany 2007). In some cases, shallow slope failures can affect regular traffic movement if debris flows onto highway pavements.

Typically, failure occurs because of an increase in pore water pressure and reduction in soil strength due to the progressive wetting of the near-surface soil. This condition is further exacerbated by moisture variations due to seasonal climatic changes, which cause cyclic shrinkage and swelling of the upper soils. Cyclic shrinkage and swelling leads to the change in void ratio of soil and lower the shear strength. Reduction of shear strength results in sloughing and shallow slope failures which are predominant in the North Texas. It poses a significant maintenance problem to the Texas Department of Transportation (TxDOT) (Wright 2005). The depth of the shallow slope failure varies

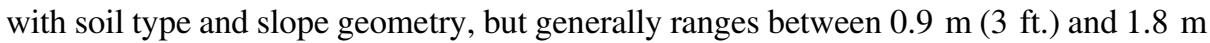
(6 ft.). (Loehr et al. 2007). Shallow failures often cause significant hazards to guard rails, shoulders, and roadways, which, if not properly maintained, may require extensive and expensive repairs.

Reinforcement is an effective remediation technique for relatively shallow slope failure conditions. In situ reinforcement methods for stabilizing slopes and embankments include soil nails, drilled piers, micro piles, and RPPs (Thompson et al. 2006). Among the available methods, the RPPs have been recognized as a cost effective solution for slope stabilization (Loehr and Bowders 2007; Khan et al. 2015). RPPs were first being utilized in the state of Missouri and Iowa, as a sustainable option to stabilize highway slopes and few field studies were conducted. The study summarized that no further failure was noticed after the slopes were stabilized using RPPs and the performance of the stabilized zone was promising (Loehr and Bowders 2007).

Typically, RPPs are fabricated from recycled plastics and waste materials (polymers, sawdust, and fly ash) (Chen et al. 2007). It is a lightweight material and less susceptible to chemical and biological degradation than other reinforcement materials. The use of RPPs can reduce the waste volume entering landfills and provide additional demand for recycled plastic (Sommers et al. 2000). A typical RPP is composed of High Density Polyethylene, HDPE (55\%-70\%); Low Density Polyethylene, LDPE (5\%-10\%); Polystyrene, PS (2\%-10\%); Polypropylene, PP (2\%-7\%); Polyethylene-terephthalate, PET (1\%-5\%); and varying amounts of additives, i.e., sawdust, fly ash (0\%-5\%) (McLaren 1995). The use of glass and wood fiber additives significantly improves the modulus of elasticity for plastic lumber (Breslin et al. 1998). RPPs driven into the slope face may provide an additional resistance along the slip plane that restricts the progression of the slip surface and increases the factor of safety. However, limited field studies have been conducted on the potential use of RPPs in slope stabilization.

The current study presents the long term performance of RPP for a highway slope stabilization. Surficial movement and a cracked shoulder were observed on a highway slope located over highway US 287 in Texas. During March 2011, two 15.25 m (50 ft.) sections on the southbound side of US 287 were reinforced using RPPs. Another cracked zone formed over the shoulder of US 287 during the following year, and a new $15.25 \mathrm{~m}(50 \mathrm{ft}$.) section was reinforced considered on the southbound slope for the stabilization, using RPPs. In addition, two $15.25 \mathrm{~m}$ (50 ft.) control sections were kept 
between the reinforced sections to compare the performance. The reinforced and control sections of the slope were monitored after installation to evaluate the performance of the slope, using instrumented RPPs, inclinometers and surveying equipment.

\section{Project Background}

The slope is located near Highway US 287, near the St. Paul overpass in Midlothian, Texas. It is a 3(H): 1(V) fill slope with $30 \mathrm{ft}$. height. Surficial movement over the slope and shoulder cracks were observed on the shoulder near the crest of the slope in September, 2010. The cracks along the pavement shoulder might have occurred due to the surficial movement of the slope. The site location and the photo of the cracked shoulder are presented in Fig. 1.

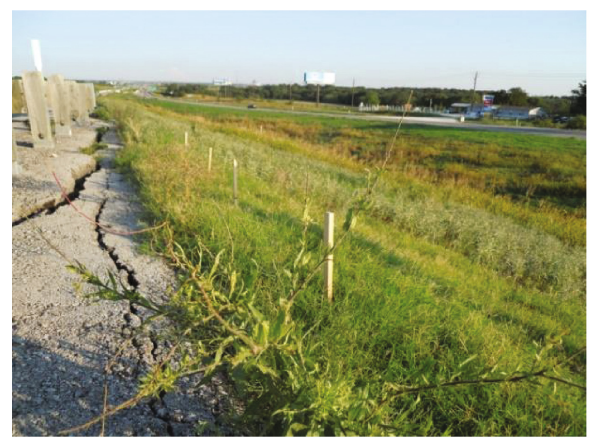

(a)

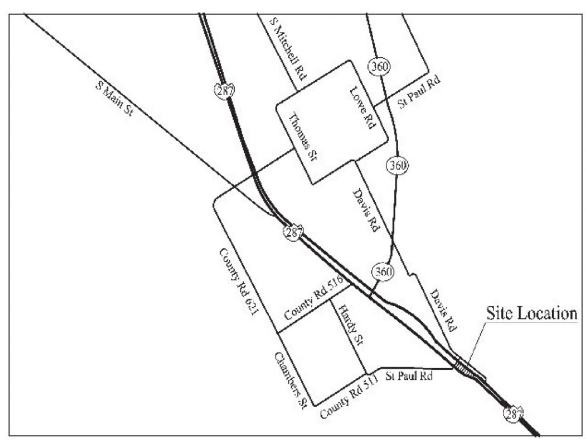

(b)

Fig. 1. (a) Site location (b) Cracks along the shoulder of Highway US 287

The geology of the location is characterized by the Eagle Ford formation. The Eagle Ford, in the project vicinity, is composed of residual soils, consisting of clay and weathered shale (shaly clay), underlain by unweathered shale. The weathered shale is claylike and contains gypsum in-fills, jointed and fractured with iron pyrites. The unweathered shale is typically gray to dark gray and commonly includes shell debris, silty fine sand particles, bentonite and pyrite. The Eagle Ford formation consists of sedimentary rock in the process of degrading into a soil mass. This formation also contains smectite clay minerals and sulfates. The smectite clay minerals are highly expansive in nature and may be a contributing factor to the expansiveness of the soil. A previous study by Kibria and Hossain (2012) indicated that the dominant mineral of the soil is montmorillonite mineral, which has high shrink/swell.

A field exploration program was undertaken, which indicated that the slope was constructed with high plastic clayey $(\mathrm{CH})$ soil. The liquid limits (LL) and plasticity indices (PI) of the samples ranged between 48 to 79 and 25 to 51 , respectively. In addition, an increase in moisture below $5 \mathrm{ft}$. was observed, which ranged up to $20 \mathrm{ft}$. Based on the back analysis with PLAXIS 2D the factor of safety was 1.05 with fully soften shear strength (Khan et al. 2015). 


\section{Slope Stabilization Using RPP}

The definition of the factor of safety of a slope is the ratio of resisting moment $\left(\mathrm{M}_{R}\right)$ to the driving moment $\left(\mathrm{M}_{\mathrm{D}}\right)$, as presented in Eq. 1. RPPs installed at the slope provided an additional resisting moment $\left(\Delta \mathrm{M}_{\mathrm{R}}\right)$ along the slip surface, thereby increasing the resistance and factor of safety, as presented in Eq. 2. The schematic diagram of RPPs as slope reinforcement is presented in Fig. 2.

$$
\begin{gathered}
\mathrm{FS}=\mathrm{M}_{\mathrm{R}} / \mathrm{M}_{\mathrm{D}} \\
\mathrm{FS}=\left(\mathrm{M}_{\mathrm{R}}+\Delta \mathrm{M}_{\mathrm{R}}\right) / \mathrm{M}_{\mathrm{D}}
\end{gathered}
$$

Where,

$\mathrm{M}_{\mathrm{R}} \quad$ = Resisting Moment along Slip Surface

$\mathrm{M}_{\mathrm{D}} \quad=$ Driving Moment along Slip Surface

$\Delta \mathrm{M}_{\mathrm{R}} \quad=$ Additional Resisting Moment from Plastic Pin.

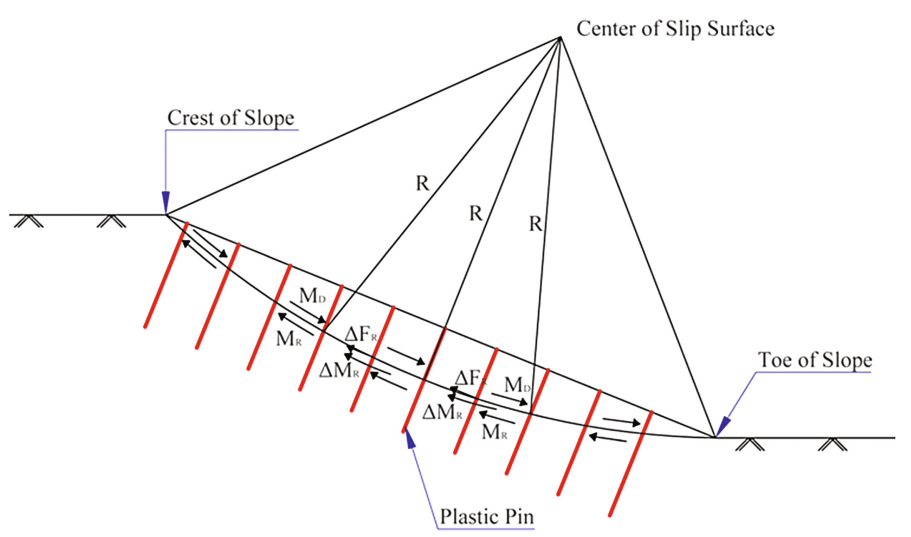

Fig. 2. Schematic diagram of slope reinforcing with RPP

Commercially available fiber reinforced RPP with square Section ( 4 in. $\times 4$ in.) and $10 \mathrm{ft}$. and $8 \mathrm{ft}$. in length was utilized as reinforcement. RPP reinforcement with different spacing, (i.e., $3 \mathrm{ft}$., $5 \mathrm{ft}$. and $6 \mathrm{ft}$. c/c), was utilized in the Reinforced Section 1. Besides, a $4 \mathrm{ft}$. c/c spacing of RPP was utilized in Reinforced Sections 2 and 3. The layout of RPP is presented in Fig. 3(a). The calculated factor of safety from the FEM model (PLAXIS 2D) was 1.43, 1.48 and 1.54 for Reinforced Sections 1, 2 and 3, respectively (Khan et al. 2014).

RPPs were installed in Reinforced Section 1 and Reinforced Section 2 on March, 


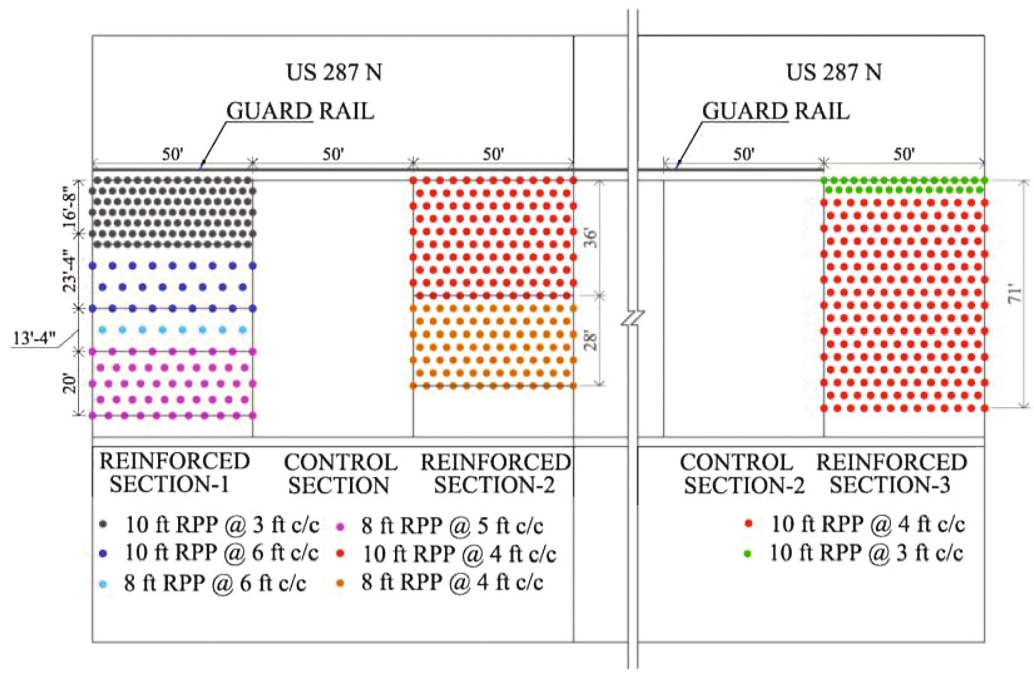

(a)

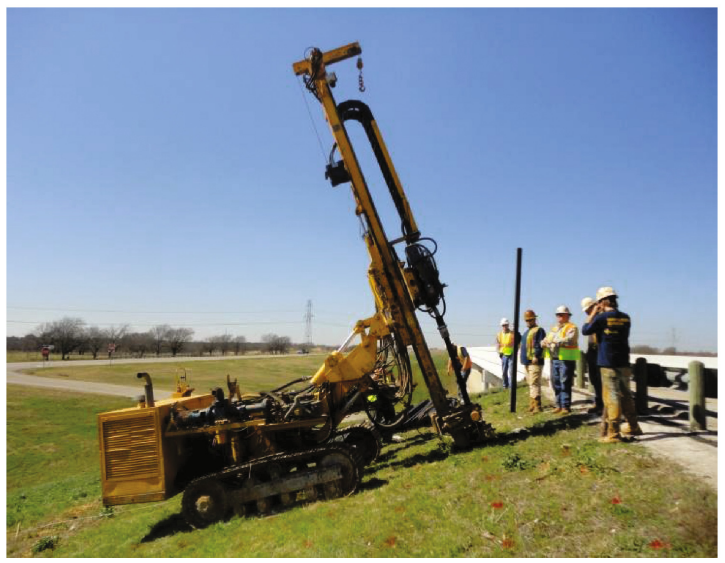

(b)

Fig. 3. (a) Layout of RPP at US 287 slope (b) Installation photo

2011, as presented in Fig. 3(b). Reinforced Section 3 was stabilized during March, 2012. A crawler-type drilling rig, having a mast-mounted vibrator hammer (model: Klemm 802 drill rig along with KD 1011 percussion head drifter), was utilized to install the RPPs. The crawler-type rig was suitable for the installation process over the slopes, as no additional anchorage was required to maintain the stability of the equipment, reducing labor, cost and time involved in the installation process. Based on 
the study, the average installation time for a $10 \mathrm{ft}$. long RPP was $4 \mathrm{~min}$, and a total of 100 to 120 RPPs could be installed in one day.

\section{Instrumentation and Performance Monitoring}

Regular topographic survey and inclinometers were used to monitor the performance of RPP stabilized slope. To evaluate the performance of the reinforced slopes and to monitor the horizontal displacement, inclinometers were installed after the completion of field installation in Reinforced Section 1 and Reinforced Section 2.

\subsection{Topographic Survey}

To compare the performance between the reinforced section and control section, topographic surveys were performed on monthly basis. The purpose of this survey was to monitor the settlement of the crest of the slope.

\subsection{Inclinometers}

A total of 3 inclinometers, (designated as Inclinometer 1, 2 and 3) were installed in Reinforced Section 1, Control Section and Reinforced Section 2 to monitor the horizontal movement of the slope. The depth of each inclinometer casing was $30 \mathrm{ft}$. and it was installed perpendicular to the slope surface, $20 \mathrm{ft}$. below the crest. The layouts of the inclinometers are presented in Fig. 4. The inclinometers were monitored on a bi-weekly basis.

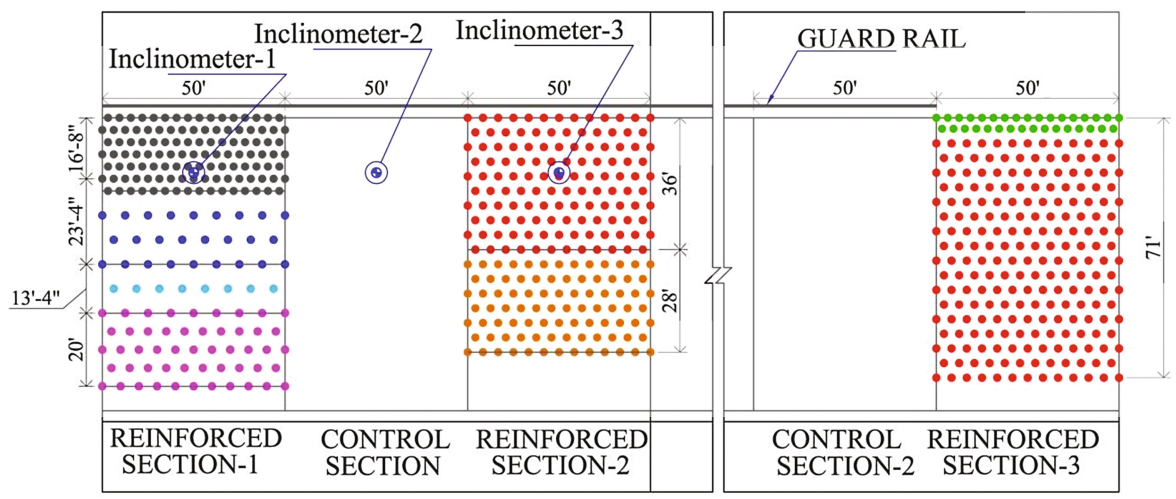

Fig. 4. Layout of inclinometer 


\section{Performance Evaluation}

\subsection{Topographic Survey}

The total settlement over the crest of the southbound slope was measured during each survey, in between, the total settlement plot for September 2016 is presented in Fig. 5. The total settlement plot shows the control sections had significantly greater settlement at the crest when compared to the reinforced sections. The maximum settlements were $38 \mathrm{~cm}$ (15 in.) and $24 \mathrm{~cm}$ (9.5 in.) in Control Section 1 and Control Section 2, respectively, while Reinforced Section 1 had the lowest settlement of $7 \mathrm{~cm}$ (2.75 in.), followed by the Reinforced Section 3 and Reinforced Section 2, with settlements of $16 \mathrm{~cm}$ (6.25 in.) and $14 \mathrm{~cm}$ (5.5 in.), respectively. It should be noted that Reinforced Section 1 had the lowest spacing of RPPs $(0.9 \mathrm{~m}, 3 \mathrm{ft} . \mathrm{c} / \mathrm{c})$ at the crest of the slope.

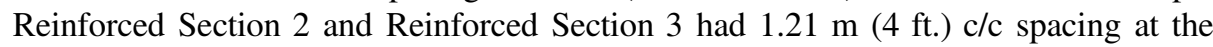
crest, which was higher and had higher deformation than Reinforced Section 1. Maximum incremental settlement on the reinforced section was less than $3.75 \mathrm{~cm}$ (1.5 in.) after five years of installation of RPPs.

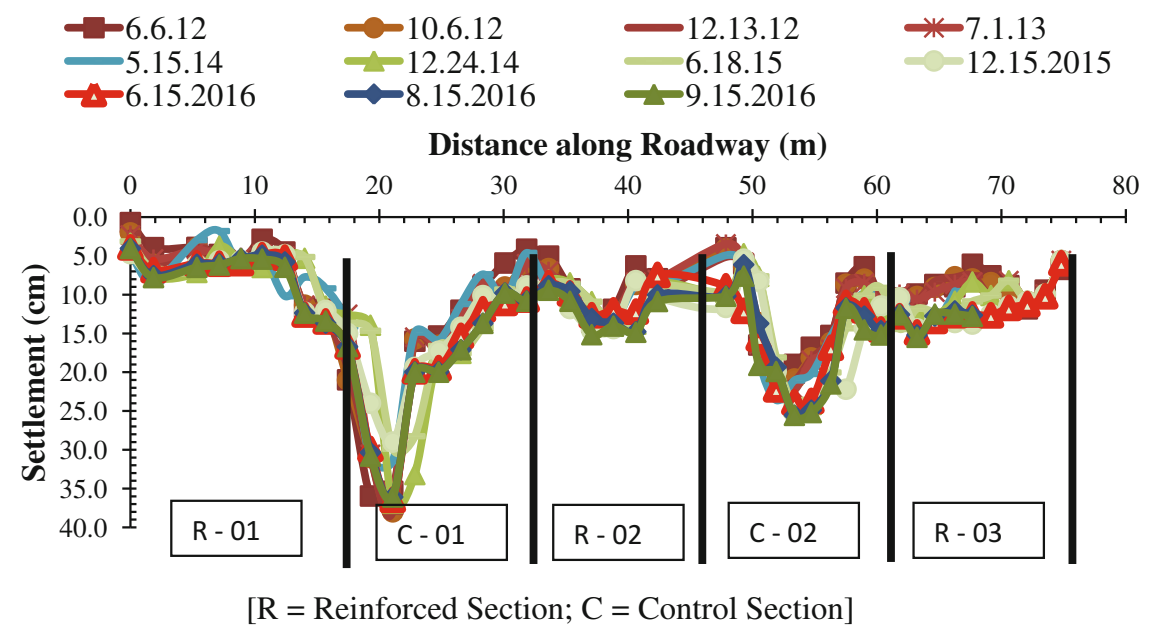

Fig. 5. Settlement at the crest of slope (Southbound side)

\subsection{Inclinometer}

The inclinometers were monitored on a monthly basis. After each monitoring, the obtained data from the inclined plane of the inclinometer was normalized to the vertical plane and the horizontal movements of Inclinometer 1 and Inclinometer 3 are shown in Figs. 6 and 7 respectively. Inclinometer 2 malfunctioned; consequently, that data is not presented here. 


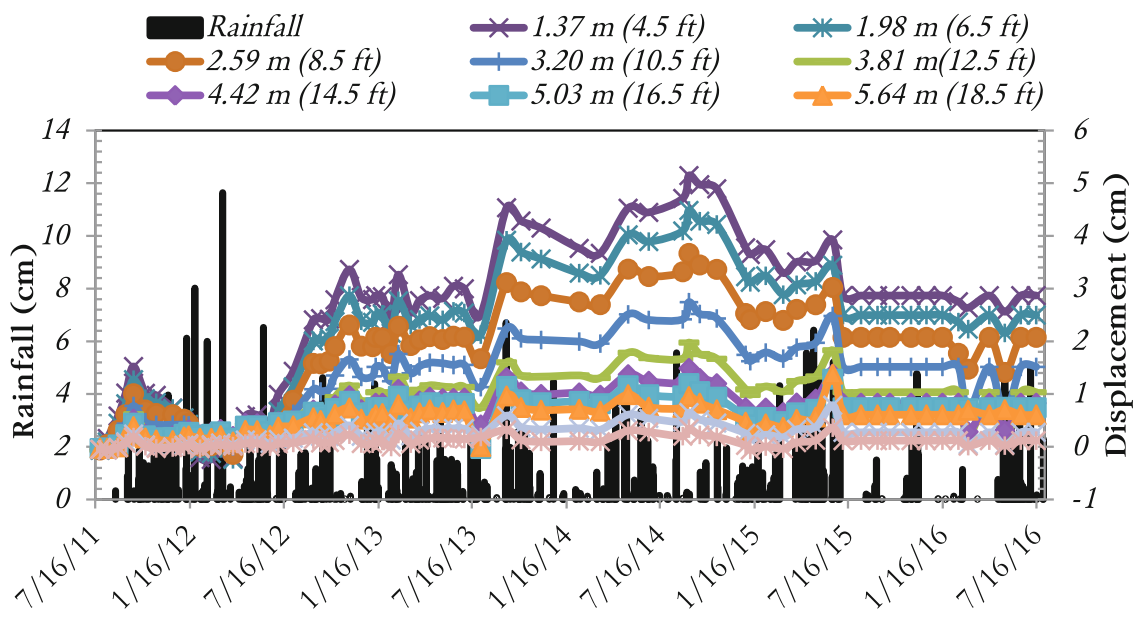

Date

Fig. 6. Inclinometer - 1: cum displacement A-A with time

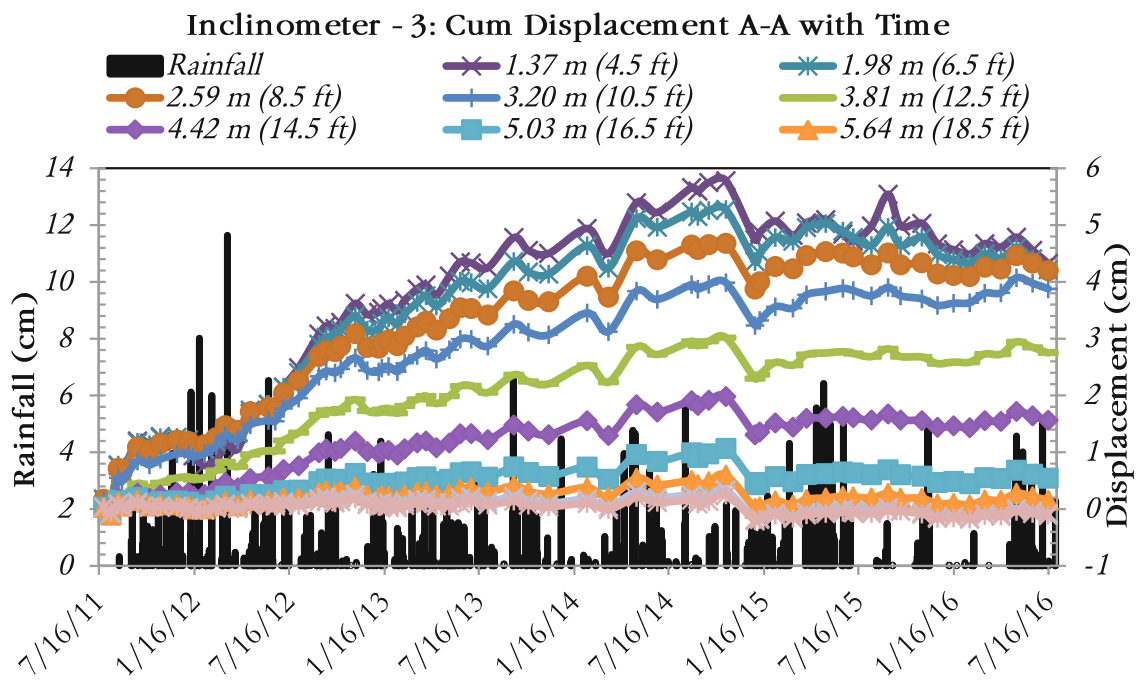

Date

Fig. 7. Inclinometer - 3: cum displacement A-A with time

The comparisons of movement between Inclinometer 1 and Inclinometer 3 at different depths $(1.37 \mathrm{~m}$ and $3.2 \mathrm{~m})$ are presented in Fig. 8. It was observed that Inclinometer 3 had higher horizontal displacement $(4.3 \mathrm{~cm})$ than Inclinometer 1 $(2.8 \mathrm{~cm})$ at $1.37 \mathrm{~m}$ depth. A similar trend was observed at $3.2 \mathrm{~m}$ depth, where the observed displacement was $3.9 \mathrm{~cm}$ and $1.6 \mathrm{~cm}$ for Inclinometer 1 and Inclinometer 3, respectively. It should be noted that the maximum horizontal displacement took place at the surface of the slope and consequently reducing with deeper depth. 


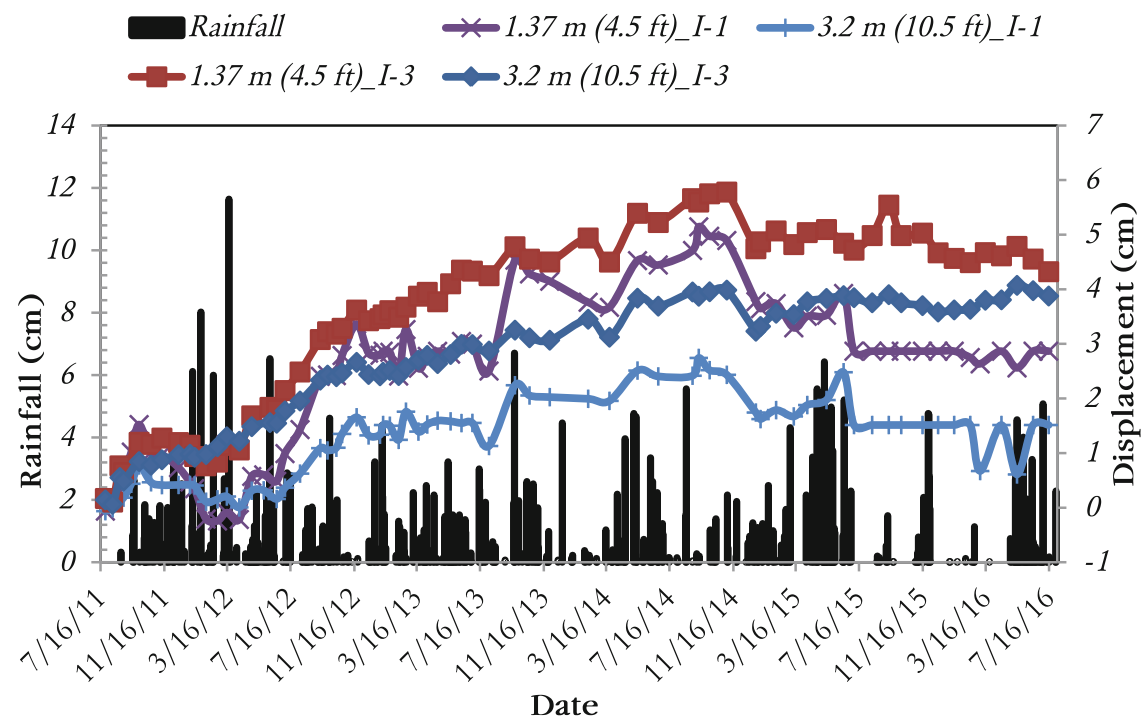

Fig. 8. Comparison of inclinometer $-1 \& 3$

Khan et al. 2014 conducted a numerical study on the slope stabilization using recycled plastic pin. During the study, the change in horizontal displacement of RPP at the crest of the slope is investigated using finite element method (FEM), with the change in RPP spacing. The FEM results indicated that, with the increment in RPP

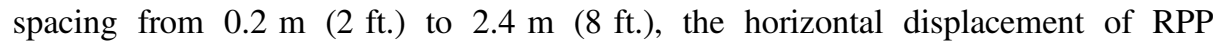
increases from $2.5 \mathrm{~cm}$ ( 1 in.) to $12 \mathrm{~cm}$ (4.7 in.). In addition, the observed horizontal displacement from FEM analysis at the crest is in good agreement with the observed

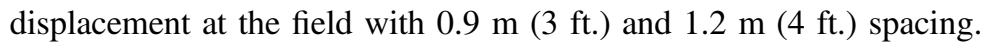

\subsection{Performance of the Northbound Slope}

The northbound slope of highway US 287 was inspected visually on a monthly basis for last five years. A number of shallow slope failures were recorded on the control (northbound of US 287) slope and the failure locations are shown in Fig. 9. Photographs of the failures of Location 1 to Location 6 are also shown in Fig. 10. First time failures (Location 1 and Location 2) on the control slope were observed during September 2013, after a rainfall event. Soil was backfilled and compacted within the failure zone during the maintenance period. But the slope failed (Location 3) again during August, 2014 after a period of a heavy rainfall. Soil was backfilled again within 


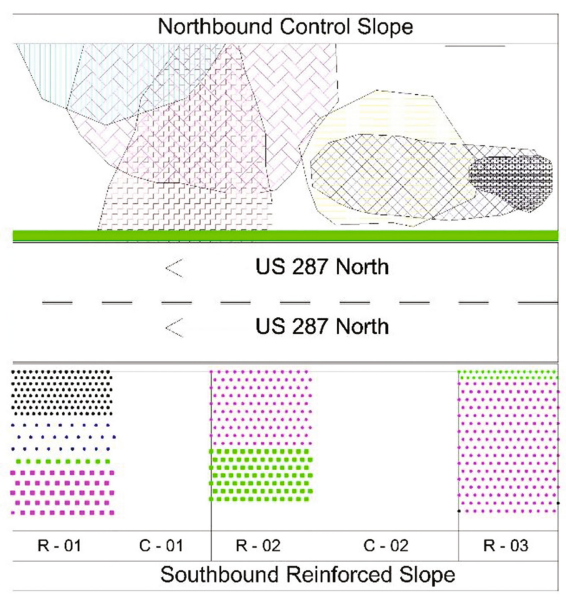

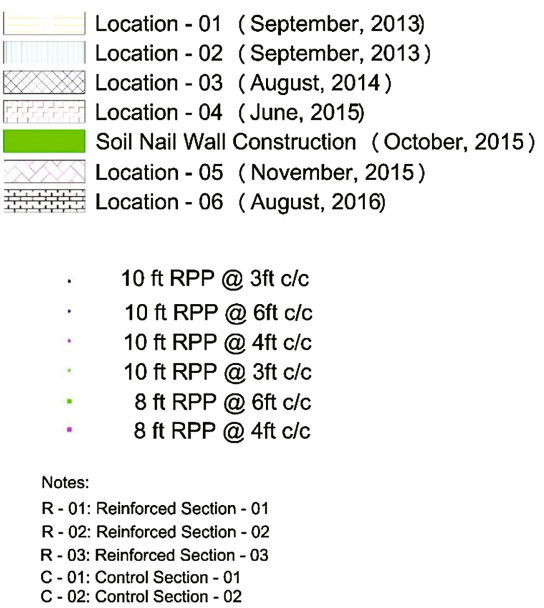

Fig. 9. Schematic diagram of slope failure within northbound control slope.

the failure location which was a temporary solution to prevent the movement of the slope. A global failure (Location 4) of the slope was observed on June, 2015 after a massive rainfall of $125 \mathrm{~mm}$ during that month. A soil nail wall was constructed to control the movement of the pavement and the whole slope was reconstructed with some geogrid reinforcement on October, 2015. Even after the reconstruction, the slope failed (Location 5) after a month of heavy rainfall. Most recent failure was recorded on August, 2016 and levelled as Location 6.

During the failures of the northbound slope, some sharp increment of horizontal displacement was observed at Inclinometer 1. The sharp increments of the horizontal displacement might indicate that the southbound slope had the tendency to slip due to the rainfall which provided additional load over the recycled plastic pin and may cause the additional movement. However, the RPP provided resistance and no sign of failure was observed at the reinforced section during the time of failure of the northbound slope. Moreover, no failure was also reported at the control section of the southbound slope. It should be noted that the control sections are located between the reinforced sections. During the failure of the northbound slope, the control section should tend to slip which might get resistance from the reinforced section. As a result, no failure was observed at the control section of the southbound slope. 

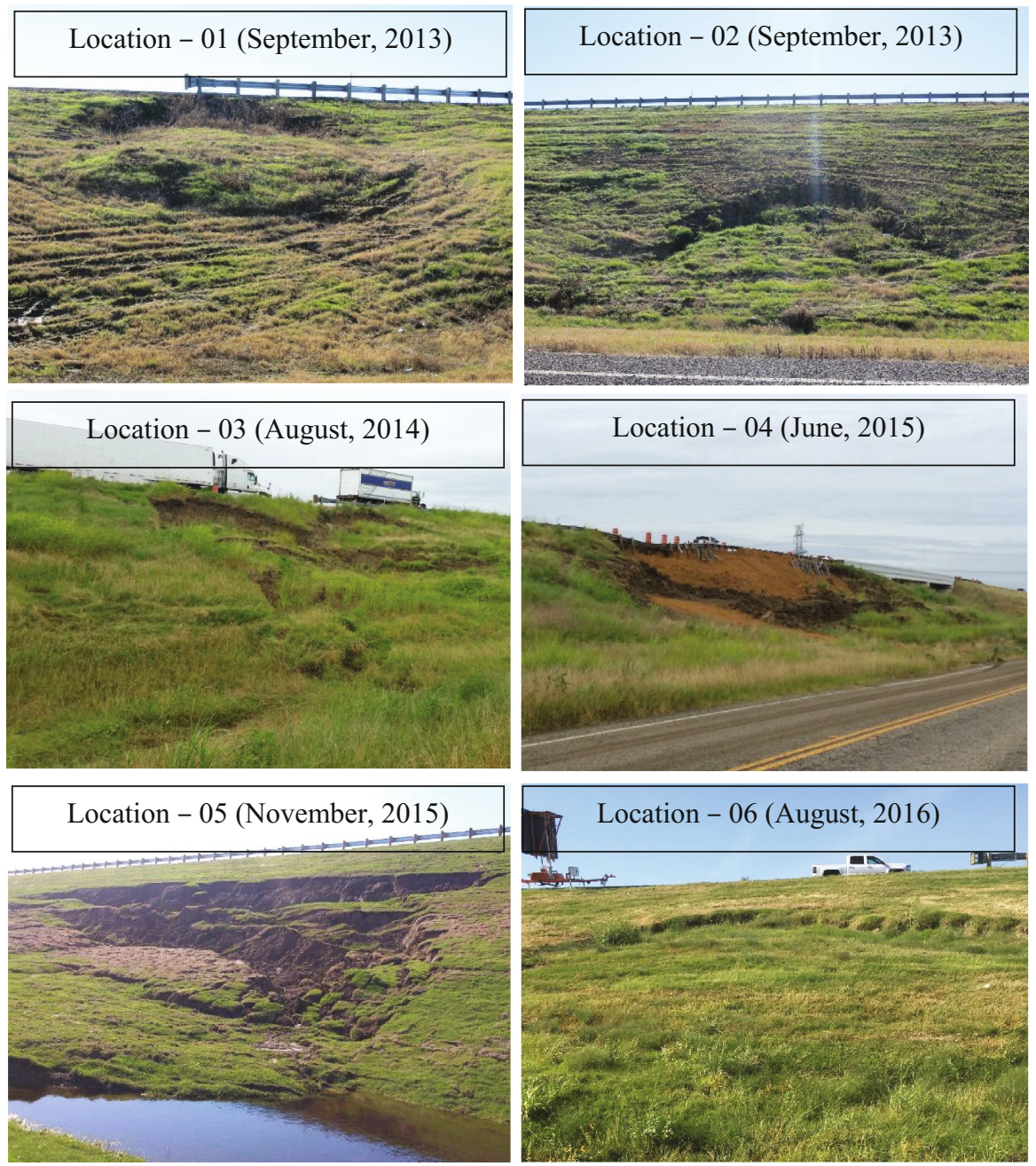

Fig. 10. Failure locations (Location 01-06) at the northbound of the US 287 slope

\section{Summary}

A highway slope located on the southbound side of highway US 287 near the St. Paul overpass in Midlothian, Texas was stabilized using RPPs. Three $15.25 \mathrm{~m}$ (50 ft.) sections were selected and reinforced, using RPPs, after a crack, caused by slope movement, was observed on the shoulder. Additionally, two $15.25 \mathrm{~m}$ (50 ft.) control sections were utilized between the reinforced sections to compare the performances between the unreinforced and reinforced slopes. The field performance of the slope was monitored using topographic survey and inclinometers. Performance monitoring results for last 5 (five) years are summarized below. 
- The unreinforced control sections of the southbound slope had significant settlement at the crest of the slope, as much as $38 \mathrm{~cm}$ whereas the incremental settlement on the reinforced section was less than $3.75 \mathrm{~cm}$.

- Maximum cumulative displacement for inclinometer 1, at a depth below 1.37 and $3.20 \mathrm{~m}$ were $2.80 \mathrm{~cm}$ and $1.60 \mathrm{~cm}$ respectively.

- Maximum cumulative displacement for inclinometer 3, at a depth below 1.37 and $3.20 \mathrm{~m}$ were $4.30 \mathrm{~cm}$ and $3.90 \mathrm{~cm}$ respectively.

- Both inclinometers showed the same trend that, cumulative displacement decreases with the depth from the slope surface.

- Having the same geographic and climatic condition, the southbound control slope failed several times at different locations.

Based on the current study, it can be concluded that the overall performance of the reinforced sections was better than that of the control sections. The northbound control slope failed several times during the monitoring period whereas no visual depression or failure was observed within the southbound slope. Since the shallow failure is a major issue for slopes constructed with high plastic clayey soil; RPPs could provide a cost effective and sustainable solution to mitigate this problem.

\section{References}

Breslin, V.T., Senturk, U., Berndt, C.C.: Long-term engineering properties of recycled plastic lumber in pier construction. Resour. Conserv. Recycl. 23(1998), 243-258 (1998)

Chen, C.W., Salim, H., Bowders, J., Loehr, E., Owen, J.: Creep behavior of recycled plastic lumber in slope stabilization applications. J. Mater. Civ. Eng. 19(2), 130-138 (2007)

Khan, M.S., Hossain, S., Kibria, G.: Stabilisation using recycled plastic pins. J. Perform. Constructed Facil. 229-234 (2017). doi:10.1201/9781315206202-11. Online publication date: 14 Jun 2017

Khan, M.S., Hossain, M., Lozano, N.: Numerical study of slope stabilization using recycled plastic pin. In: Geo-Congress 2014 Technical Papers: Geo-characterization and Modeling for Sustainability, pp. 3092-3101. ASCE, February 2014

Kibria, G., Hossain, M.S.: Investigation of geotechnical parameters affecting electrical resistivity of compacted clays. J. Geotech. Geoenviron. Eng. (2012). doi:10.1061/(ASCE)GT.19435606.0000722

Loehr, J.E., Bowders, J.J.: Slope Stabilization using Recycled Plastic Pins - Phase III. Final report: RI98-007D, Missouri Department of Transportation, Jefferson City, Missouri (2007)

Loehr, J.E., Fennessey, T.W., Bowders, J.J.: Stabilization of surficial slides using recycled plastic reinforcement. Transp. Res. Rec. J. Transp. Res. Board 2, 79-87 (2007). No. 1989

McLaren, M.G.: Recycled plastic lumber and shapes design and specification. In: Proceedings 13th Structures Congress, ASCE, vol. 1, pp. 819-833 (1995)

Sommers, L., Loehr, J.E., Bowders, J.J.: Construction methods for slope stabilization with recycled plastic pins. In: Proceedings of the Mid-continent Transportation Symposium, Iowa State University, Ames, Iowa, 15-16 May 2000

Thompson, M.J., White, D.J.: Design of reinforcement with small-diameter piles. In: Proceedings of Advances in Earth Structures: Research to Practice, GSP no. 151, pp. 1-12 (2006). Reston/VA 
Titi, H., Helwany, S.: Investigation of Vertical Members to Resist Surficial Slope Instabilities (No. WHRP 07-03). Wisconsin Department of Transportation, Madison, WI (2007)

Wright, S.G.: Evaluation of Soil Shear Strengths for Slope and Retaining Wall Stability Analyses with Emphasis on High Plasticity Clays. Federal Highway Administration, Washington, D.C. (2005). FHWA/TX-06/5-1874-01-1 